\title{
Synthesis and Bio-Spectral Studies of Co(II) Complex of 5-Chloro-2,4- Dihydroxy Butyrophenoneoxime (CDHBOX)
}

\author{
+ F.Rehman*, M.Bhardwaj ${ }^{*}$, and U.K. Jetley** \\ rehman12366@yahoo.com, ukjetley@gmail.com \\ *Deptt. of Analytical Chemistry, Faiz-E-Aam Degree college, Meerut.U.P, India \\ ${ }^{* *}$ Deptt. Of Applied Science, HRIT, Gaziabad, U.P., India
}

\begin{abstract}
Co(II) complex of 5-chloro-2,4-dihydroxy butyrophenoneoxime (CDHBOX) was synthesized from 5-chloro-2,4dihydroxy butyrophenoneoxime by using standard protocol, and characterized by elemental analyses, melting point determination and spectral data. The $\mathrm{ML}_{2}$ (metal/ligand) stoichiometry of the complex was determined by spectrophotometric and potentiometric studies, and mass spectral data. The value of stability constant of the complex was found to be $6.94 \times 10^{8}$ while its standard free energy of formation is $12.155 \mathrm{kcal} / \mathrm{mol}$ at $27^{\circ} \mathrm{C}$. Beer's law is obeyed in the concentration range $2-15 \mathrm{ppm}$ of Co. The value of molar extinction coefficient and sensitivity as per Sandell's scale were

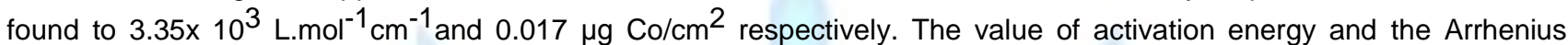
constant Arrhenius constant were found as $4.949 \mathrm{kjmol}^{-1}, 74.39$. The IR studies reveal that the phenolic proton is lost on complexation and the oxygen of the phenolic $(-\mathrm{OH})$ and nitrogen of the oximino $(=\mathrm{NOH})$ groups coordinate with $\mathrm{Co}(\mathrm{II})$ ion. The electronic spectra and magnetic susceptibility measurement indicate that the complex is paramagnetic and tetrahedral in nature. The antimicrobial activity of different concentrations of ligand and its $\mathrm{Co}$ (II)-complex has been evaluated against Curvularia lunata, Fusarium oxysporum and Alternaria alternata fungi and Streproproteus, Staph, Escherchia coli, Klebsella, and pseudomonas bacteria. The results indicated that the ligand (CDHBOX) and its Co(II) complex have good anti-microbial properties.
\end{abstract}

Key words: Co(II)-complex; Spectra; Thermodynamic parameters; Antimicrobial screening.

\section{Council for Innovative Research}

Peer Review Research Publishing System

\section{Journal: Journal of Advances in Chemistry}

Vol. 6, No. 3

editor@cirworld.com

www.cirworld.com, member.cirworld.com 


\section{Introduction}

Phenones and their oximes have been widely used as antiseptics, germicides, anthelmintics, analgesics[1], antituberculotics[2], against mycobacteria[3] and also show antimicrobial

(antibacterial and antifungal) [4-5], antiviral[6] and antimutagenic activity[7]. Their use as herbicides is also reported [8]. Paeonol forms sulfated derivative when orally administered to rats which is excreted with urine [9]; so, no apparent toxicity was exhibited with numerous doses upto $50 \mathrm{mg} / \mathrm{kg}$. In the last few years, there has been a great surge in the development of chelation chemistry and its use in medicine and related areas of life science research. Chelating agents containing oxygen, sulpher and nitrogen as donar atoms especially exhibit broad biological activity, and are of special interest due to their binding behavior to metal ions[10].The presence of transition metals in human blood plasma indicates their importance in the mechanism for accumulation, storage and transport of transition metals in living organisms and their key role in biological systems such as cell division, respiration, nitrogen fixation and photosynthesis[11]. A number of phenones have aroused considerable interest as regards to their chelating ability with transition metal ions[12-14], and their use as excellent analytical reagents[15] for gravimetric and spectrophotometric determination of transition metal ions[16-18]. The study of phenones and its Metal(II) complexes has a peculiar importance from pharmacological point of view. Most butyrophenone are neuroleptic drugs that control schizophrenic symptoms and has been used to treat numerous phychological disorders and are effective as antiemetic which prevent nausea and vomiting. So, the present communication deals with the synthesis of Co(II)- CDHBOX complex, its characterization by elemental analyses and spectral data, and its investigation by potentiometric, spectrophotometric, mass spectral and thermal studies and magnetic susceptibility measurement. The antimicrobial activity of CDHBOX and its Co(II)- complex has also been evaluated against selected bacteria and fungi by using standard protocols[22,23], and the results compared with standard drugs.

\section{Experimental}

\subsection{Materials}

Resorcinol, butyric acid, anhydrous zinc chloride, con. $\mathrm{HCl}, \mathrm{KMnO}_{4}$ and hydroxylamine hydrochloride (Glaxo Ltd) respectively were used for the preparation of CDHBOX. The chloride of cobalt(II) ion was used as its hydrated salt. Anhydrous sodium acetate, perchloric acid, sodium perchlorate and the required solvents (ethanol, dioxane,dimethylformamide,etc.) used in the work were of analytical grade, purchased commercially. The solvents used were purified / dried by recommended procedures[19].

\subsection{Physical measurements}

The elemental analyses were carried by Elementar Vario EL III Model, and the estimation of metal was performed by AA640-13 Shimadzu flame atomic absorption spectrophotometer. A Systronic spectrocolorimeter (Type 103) was used for the absorbance measurements and $\mathrm{pH}$ measurements were made on a Systronic(335) digital $\mathrm{pH}$ - meter, and the values corrected by using Van Uitert and Hass equation[20]. The electronic spectrum of the complex was recorded on Beckman DU-64 spectrophotometer. The IR spectra of the ligand and its metal complex were recorded on Perkin Elmer FT-IR spectrophotometer in $\mathrm{KBr}$; their NMR spectra was recorded by high performance FT-NMR spectrometer. The FAB mass spectrum of the complex was recorded at USIC facility at IIT, Roorkee. Magnetic susceptibility measurement was carried out at room temperature by using powdered sample on a vibrating sample magnetometer PAR 155 with 5000 G-field strength, using $\mathrm{Hg}\left[\mathrm{Co}(\mathrm{CNS})_{4}\right]$ as a calibrant. TG curve was recorded by Rigaku Model 8150 thermo-analyzer at the

heating rate of $5^{\circ} \mathrm{min}^{-1}$. The instrument was calibrated by calcium oxalate for TG. The TG curve helped to identify the number of decomposition steps. The thermodynamic activation parameters such as $\mathrm{E}, \Delta \mathrm{H}, \Delta \mathrm{S}$ and $\Delta \mathrm{G}$ were calculated from potentiometric data, using Coats and Redfern method[32].

\subsection{Synthesis of 2,4-dihydroxy butyrophenone(DHB)}

It was prepared by condensing resorcinol $(0.1 \mathrm{~mol})$ with butyric acid $(0.1 \mathrm{~mol})$ in the presence of anhydrous zinc chloride $(0.1 \mathrm{~mol})$. The reaction mixture was kept at $160-165^{\circ} \mathrm{C}$ for half an hour. It was then cooled and poured in ice cold $50 \%$ hydrochloric acid. The precipitated product 2,4-dihydroxy butyrophenone (DHB) was filtered, and crystallized from ethanol. The purity was checked by melting point $\left(65^{\circ} \mathrm{C}\right)$ and TLC.

\subsection{Synthesis of 5-chloro-2,4-dihydroxy butyrophenone (CDHB)}

5- chloro-2,4-dihydroxy butyrophenone $(0.1 \mathrm{~mol})$ was dissolved in minimum quantity of ethanol in around bottomed flask fitted with an inlet tube and a reflux condenser. Dry chlorine gas was then passed into the flask through the inlet tube maintaining the temperature of the solution between $70-80^{\circ} \mathrm{C}$. The product was filtered, and crystallized from aqueous ethanol. The purity was checked by melting point $\left(95^{\circ} \mathrm{C}\right)$ and TLC.

\subsection{Synthesis of 5-chloro-2,4-dihydroxy butyrophenone oxime (CDHBOX)}

CDHBOX was prepared as reported earlier [21], and purified/dried by the recommended procedure [19]. 


\subsection{Isolation of $\mathrm{Co}(\mathrm{II})$ complex of HMAOX}

$50 \mathrm{ml}$ of $0.2 \mathrm{M}$ aqueous solution of $\mathrm{CoCl}_{2}$ was added to $100 \mathrm{ml}$ of $0.4 \mathrm{M}$ solution of 5-chloro-2,4-dihydroxy butyrophenoneoxime in $50 \%$ ethanol, and the mixture was stirred for about an hour at room temperature. The Co(II)CDHBOX complex seperated as a orange

precipitate within the $\mathrm{pH}$ range 4.5-7.9. The precipitated complex was digested, filtered and washed first with hot water and then with $25 \%$ ethanol, and finally dried at $105-110^{\circ} \mathrm{C}$ in an air oven. The complex was analyzed for $\mathrm{C}, \mathrm{H}, \mathrm{N}$ and metal content $[\mathrm{C}=46.45(46.51), \mathrm{H}=4.30$

(4.26), $\mathrm{N}=5.40(5.42), \mathrm{Cl}=13.72(13.76)$ and $\mathrm{Co}=11.48911 .43)]$,

The results of elemental analyses revealed a 1:2 (metal:ligand) stoichiometry for the complex. The 1:2 (M:L) stoichiometry was also verified by spectrophotometric studies and FAB mass spectrum.

The general composition of the complex could thus be formulated as $\left[\mathrm{C}_{20} \mathrm{H}_{22} \mathrm{~N}_{2} \mathrm{O}_{6} \mathrm{Co}\right.$.

\subsection{Potentiometric studies}

Calvin and Bjerrum technique [27] was used to determine stability constant of the complex by evaluating $\bar{n}, \bar{n} \mathrm{H}$ and $\mathrm{pL}$ values at different temperatures, and concentrations by using standard formulae [28].

The following solutions were titrated against standard carbonate free sodium hydroxide ( $0.05 \mathrm{M})$ to carry out potentiometric studies:
A. $2.0 \mathrm{ml} \mathrm{HClO}_{4}(0.05 \mathrm{M})+4.0 \mathrm{ml} \mathrm{NaClO}_{4}(1.0 \mathrm{M})+4.0 \mathrm{ml} \mathrm{H}_{2} \mathrm{O}+30.0 \mathrm{ml}$ dioxane.
B. $2.0 \mathrm{ml} \mathrm{HClO}_{4}(0.05 \mathrm{M})+4.0 \mathrm{ml} \mathrm{NaClO}_{4}(1.0 \mathrm{M})+4.0 \mathrm{ml} \mathrm{H}_{2} \mathrm{O}+10.0 \mathrm{ml}$ ligand $(0.01 \mathrm{M})+20.0 \mathrm{ml}$ dioxane.
C. $2.0 \mathrm{ml} \mathrm{HClO}_{4}(0.05 \mathrm{M})+4.0 \mathrm{ml} \mathrm{NaClO}_{4}(1.0 \mathrm{M})+1.5 \mathrm{ml} \mathrm{H}_{2} \mathrm{O}+2.5 \mathrm{ml}$ metal solution $(0.008 \mathrm{M})+10.0 \mathrm{ml}$ ligand $(0.01 \mathrm{M})+20.0 \mathrm{ml}$ dioxane.

\subsection{Spectrophotometric studies}

A Systronic spectrocolorimeter (Type 103) was used for the absorbance measurement while pH value was adjusted on a Systronic (335) digital pH-meter. The nature of complex was determined by Vosburg and Cooper method [30], and its composition was known by using standard protocol [31].

\subsection{Biological studies}

\subsubsection{Antibacterial screening}

The antibacterial activitiy of the test compounds (CDHBOX and its Co-complex) was measured by paper disc diffusion method [22] using agar nutrient medium and $5 \mathrm{~mm}$ diameter paper discs of Whatman No. 1 filter paper. The filter paper discs were soaked in a solution of known amount $(0.05$ to $0.40 \% \mathrm{w} / \mathrm{v})$ of test compounds and a standard specimen (prepared in DMF), dried and laid on the surface of petri-plates which were already seeded with the test organism Streproproteus, Staph, Escherichia coli. Klebsella, and pseudomonas bacteria. All the agar dishes were then incubated in an incubator at $27 \pm 1^{\circ} \mathrm{C}$ for about 48 hours. After incubation for the stated period, the growth of the micro-organism was measured in terms of inhibition zone $(\mathrm{mm})$, formed in each disc in the form of a turbid layer, except in the region where the concentration of antibacterial agent is above the MIC. The size of the zone of inhibition depends upon sensitivity of the organism, nature of the culture medium, incubation conditions, rate of diffusion of the agent, and the concentration of the antibacterial agent.

\subsubsection{Antifungal screening}

The antifungal activity of different concentrations $(0.05$ to $0.40 \% \mathrm{w} / \mathrm{v})$ of test compounds and a standard specimen ( prepared in DMF), was measured by determining the growth of test fungi Curvularia lunata, Fusarium oxysporum and Alternaria alternata by dry weight increase method. Richard liquid medium was used as culture medium [23] in the experiment. The test compound of varying concentration $(0.05$ to $0.40 \% \mathrm{w} / \mathrm{v})$ was directly added in to the Richard liquid medium carrying the test fungus in a sterilized chamber, and was kept for seven days in an incubation chamber at $27 \pm 1^{\circ} \mathrm{C}$ . Media with test solution served as treated while that without it as check. The resultant mycelial mats in each set were carefully removed, washed, dried and then weighed separately. The percentage inhibition was calculated by the following formula:

Percentage inhibition of fungal growth $=\frac{(\mathrm{Cg}-\mathrm{Tg}) \times 100}{\mathrm{Cg}}$

where, $\mathrm{Cg}$ = average growth in the check set

$\mathrm{Tg}=$ average growth in the treated set

Activity index ( A.I. ) was also calculated using the standard formula [5]. 


\section{Results and Discussion}

The complexation reaction between metal ions and the ligand may be represented as

$$
\mathrm{CoCl}_{2}+2 \mathrm{HL} \rightarrow\left[\mathrm{CoL}_{2}\right]+2 \mathrm{HCl}
$$

\subsection{Spectrophotometric studies}

Vosburg and Cooper method [30] shows that Co(II) ion forms only one complex with CDHBOX having $\lambda_{\max }$ at $410 \mathrm{~nm}$ in the $\mathrm{pH}$ range 7.5-9.0 .

The absorbance was measured at room temperature at regular intervals of time up to two weeks, and also at different temperatures varying from $300 \mathrm{~K}$ to $325 \mathrm{~K}$. The results showed that the complex is stable for one week at $318 \mathrm{~K}$ without any change in absorbance. The optimum $\mathrm{pH}$ range for the complexation was 8.0 . It was also found that a four fold excess of the reagent was necessary to attain the maximum colour intensity.

The composition of the complex was found to be 1:2 ( metal : Ligand) by job's method, mole ratio and slope ratio method[Fig1-3]. The stability constant of the complex was calculated using the following equation:

$$
K=c(1-\alpha) /(m a c)^{m}(n \alpha c)^{n}, \alpha=E_{m}-E_{s} / E_{m} \text {. }
$$

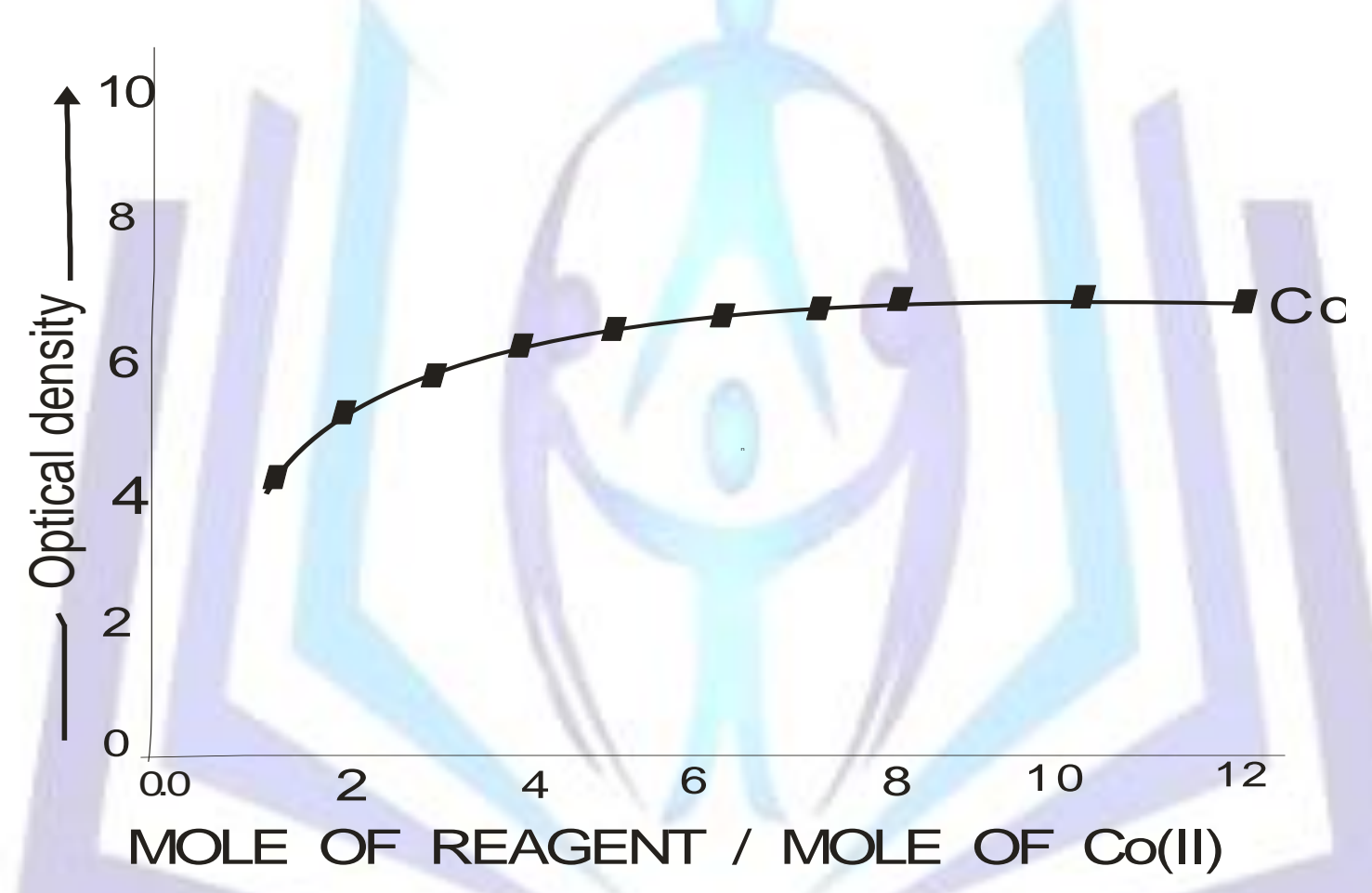

COMPOSITION OF THE CO(II)- CDHBOX COMPLEX BY MOLE RATIO METHOD

Fig 1 


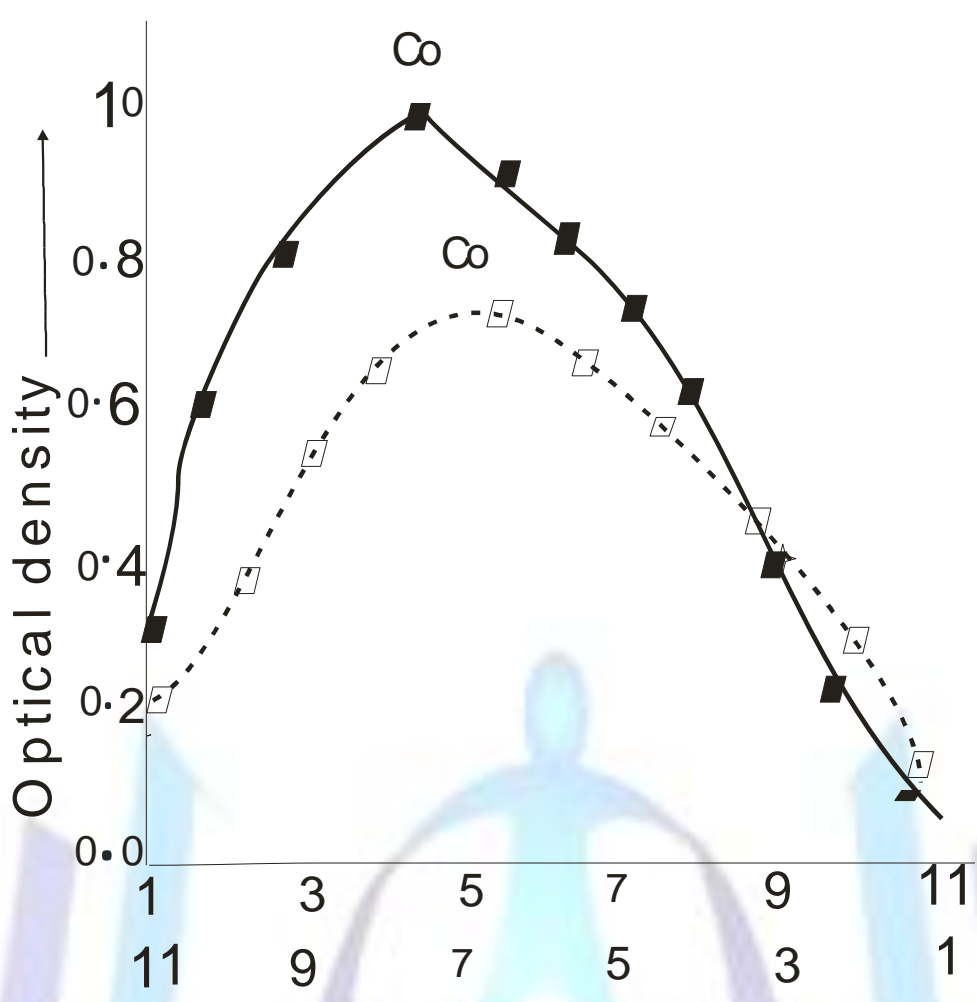

COMPOSITION OF THE CO(II)- CDHBOX COMPLEX BY JOB'S METHOD.

Fig 2

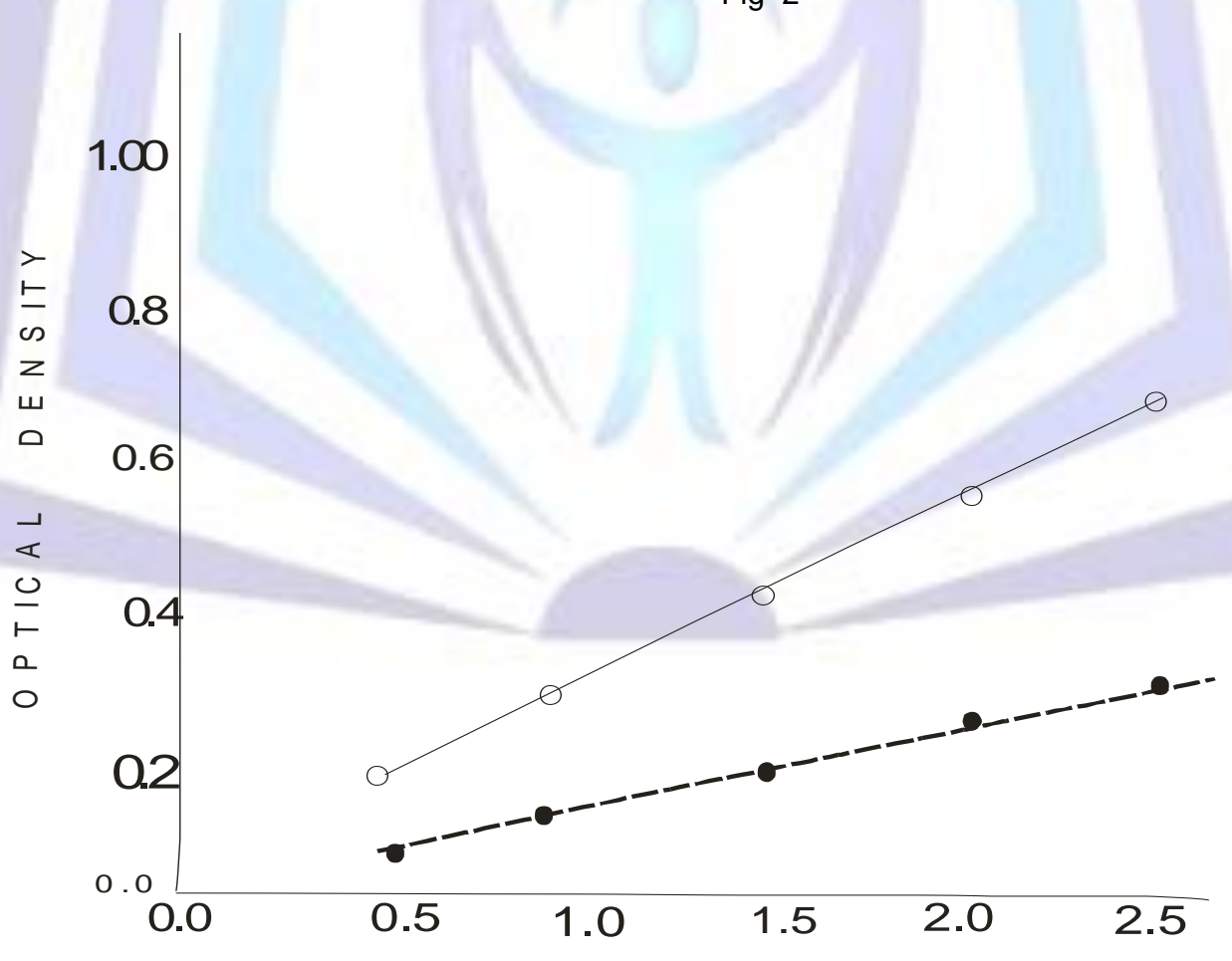

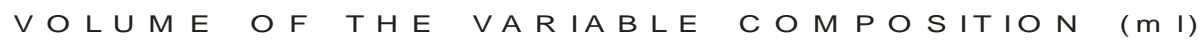
COPOSITION OF THE Co(II)-CDHBOX COMPLEX BY SLOPE RATIO METHOD

Fig 3 
Absorbance measurements of a set of six solutions prepared in a similar way, and having the same concentration of all the reagents, show that the reproducibility of measurements is quite good with a standard deviation of $0.26 \%$.

The stability constant of the complex is found to be $6.94 \times 10^{8}$, and the value of standard free energy of formation is $12.155 \mathrm{kcal} / \mathrm{mol}$ at $27^{\circ} \mathrm{C}$.

Beer's law is obeyed in the concentration range 2-15 ppm of Co. The value of molar extinction coefficient and sensitivity as per Sandell's scale are $3.35 \times 10^{3} \mathrm{~L} \mathrm{~mol}^{-1} \mathrm{~cm}^{-1}$ and $0.017 \mu \mathrm{g} \mathrm{Co} / \mathrm{cm}^{2}$ respectively.

\subsubsection{Effect of foreign ions}

The effect of foreign ions on the spectrophotometric determination of cobalt was studied by adding these ions in quantities ranging from 50 to $2000 \mathrm{ppm}$ to a solution containing a known amount of cobalt. After adjusting the $\mathrm{pH}$ of the solution at 8.0, cobalt was extracted as $\mathrm{Co}(\mathrm{II})$-CDHBOX complex in the usual manner, and the absorbance of the organic layer measured.

It was observed that $8 \mathrm{ppm}$ of $\mathrm{Co}(\mathrm{II})$ ion; $2000 \mathrm{ppm}$ of $\mathrm{Cl}^{-}, \mathrm{SO}_{4}^{2-}$ and $\mathrm{CH}_{3} \mathrm{COO}^{-}$ions; $1500 \mathrm{ppm} \mathrm{of}$ $\mathrm{NH}_{4}^{+}, \mathrm{K}^{+}, \mathrm{Na}^{+}, \mathrm{NO}_{3}^{-}, \mathrm{Br}^{-}$and $\mathrm{I}^{-}$ions; $750 \mathrm{ppm}$ of $\mathrm{SO}_{3}^{2-}$ and $\mathrm{NO}_{2}^{-}$ions $; 1000 \mathrm{Ca}^{2+}, \mathrm{Sr}^{2+}, \mathrm{Ba}^{2+}$, citrate and tartarate ions; and $200 \mathrm{ppm}$ of $\mathrm{Zn}^{2+}, \mathrm{Cd}^{2+}$ and $\mathrm{Be}^{2+}$ ions could be tolerated. However $\mathrm{Cu}^{2+}, \mathrm{Pd}^{2+}, \mathrm{Co}^{2+}, \mathrm{Fe}^{3+}$ and $\mathrm{UO}_{2}^{2+}$ ions interfered seriously. A limit of $2.0 \%$ change in the absorbance was observed as the limiting concentration.

\subsection{Magnetic moment and Electronic spectrum}

The observed magnetic moment value (4.31 B.M.) of $\mathrm{Co}(\mathrm{II})-\mathrm{CDHBOX}$ complex indicates the present complex is paramagnetic and has tetrahedral geometry. The bands occurring at 4056, 7285, and $18690 \mathrm{~cm}^{-1}$ in the electronic spectrum of the complex correspond to the ${ }^{4} A_{2}(\mathrm{~F}) \rightarrow{ }^{4} T_{2}(F),{ }^{4} A_{2}(\mathrm{~F}) \rightarrow{ }^{4} T_{2}(F)$ and ${ }^{4} A_{2}(\mathrm{~F}) \rightarrow{ }^{4} T_{2}(P)$ transitions respectively. The values of $B^{\prime}, \beta$ and $\lambda$ were also calculated. The values of $\beta$ is comparable to that reported for a tetrahedral complex.

\subsection{Infrared spectra and mode of bonding}

The IR spectra of metal chelate and of free ligand were recorded both in the high frequency region $\left(650-4000 \mathrm{~cm}^{-1}\right)$ and low frequency region $\left(50-650 \mathrm{~cm}^{-1}\right)$. In general, vibrations which occur in the high frequency region, originate due to the ligand itself whereas those in the lower frequency region originate due to the metal- ligand bonds (Table 1). In CDHBOX, the broad band at $3320 \mathrm{~cm}^{-1}$ has been assigned to the phenolic $\mathrm{OH}$ group. The band at $3270 \mathrm{~cm}^{-1}$ is due to $=\mathrm{NOH}$ group The band at $2970 \mathrm{~cm}^{-1}$ and $2870 \mathrm{~cm}^{-1}$ are due to $\mathrm{C}-\mathrm{H}$ stretching vibrations, the band at $1670 \mathrm{~cm}^{-1}$ is due to $\mathrm{C}=\mathrm{N}$ stretching, the bands at $760 \mathrm{~cm}^{-1}$ are due to the presence of $\mathrm{C}-\mathrm{Cl}$ stretching and the band at $990 \mathrm{~cm}^{-1}$ is due to N-O stretching. The band at $1190 \mathrm{~cm}^{-1}$ further confirms benzene ring substitution. The absence of band at $3320 \mathrm{~cm}^{-1}$ and a strong band of the free ligand at $1290 \mathrm{~cm}^{-1}$ is due to $\mathrm{C}-\mathrm{OH}$ (phenolic) shift to higher frequency region in the complex which indicates deprotonation of the phenolic group, and coordination of the phenolic oxygen to Co(II) ion. The shifting of broad and low intensity band due to $\mathrm{v}(\mathrm{O}-\mathrm{H})$ mode of $\mathrm{N}-\mathrm{OH}$ group from $3270 \mathrm{~cm}^{-1}$ to $3250 \mathrm{~cm}^{-1}$ suggests weakening of $\mathrm{N}$ $\mathrm{OH}$ bond due to the formation of $\mathrm{Co}-\mathrm{N}$ bond. The coordination of the oximino group through nitrogen is indicated by lowering of the $\mathrm{C}=\mathrm{N}$ band from $1670 \mathrm{~cm}^{-1}$ in the ligand to $1630 \mathrm{~cm}^{-1}$ in the metal complex. Shifting of the $\mathrm{N}-\mathrm{O}$ band at $990 \mathrm{~cm}^{-1}$ in CDHBOX to $1015 \mathrm{~cm}^{-1}$ in the metal complex further suggests the participation of nitrogen of the oximino group in the complexation with the formation of a Co- $\mathrm{N}$ bond. In the IR spectrum of the complex, the bands observed at $655 \mathrm{~cm}^{-1}$ and $470 \mathrm{~cm}^{-1}$ are assigned to the Co- $\mathrm{N}$ and Co-O stretching vibrations [24]. A band at $1368 \mathrm{~cm}^{-1}$ belonging to the benzene $\mathrm{v}(\mathrm{C}=\mathrm{C})$ is affected on complexation showing that the ligand is coordinated to metal through the oxygen of hydroxyl group of benzene ring [25]. It is observed that the aliphatic protons are not greatly affected on complexation [26].

It is clear from the above discussion that the free ligand interacts with $\mathrm{Co}$ (II) ion resulting in the formation of a metal-ligand complex. 
Table 1 Significant peaks of CDHBOX and its Co(II) complex in the IR spectra

(value in $\mathbf{c m - 1 )}$

\begin{tabular}{|l|l|l|}
\hline $\mathrm{HL}$ & $\mathrm{MnL}_{2}$ & Tentative Assignment \\
\hline 3320 & - & OH Stretching(hydrogen bonded) \\
\hline 3270 & $3250(\mathrm{~m})$ & OH Stretching (N-OH) \\
& $3170(\mathrm{~s})$ & \\
\hline $2970(\mathrm{~s}), 2870(\mathrm{~m})$ & $2955(\mathrm{~s})$ & $\mathrm{C}-\mathrm{H}$ Stretching \\
\hline 1670 & $1640(\mathrm{~s})$ & $\mathrm{C}=\mathrm{N}$ Stretching \\
\hline 1290 & & \\
\hline $760(\mathrm{~s})$ & 1298 & C-O(phenolic) Stretching \\
\hline 900 & $770(\mathrm{~s})$ & C-Cl Stretching \\
\hline
\end{tabular}

\section{$3.4{ }^{1} \mathrm{H}-\mathrm{NMR}$ spectra}

${ }^{1} \mathrm{H}$ - NMR spectra of the ligand and its $\mathrm{Co}(\mathrm{II})$ complex were recorded in $\mathrm{CDCl}_{3}$. The absence of the phenolic $\mathrm{OH}$ proton signal (8.64ס) in the CDHBOX-Co(II) complex indicates coordination of phenolic oxygen to the Co(II) ion after deprotonation. The NMR spectral data of CDHBOX and its Co (II) complex are appended in Table 2.

Table 2 'H-NMR spectral data of CDHBOX and Co(II) complex

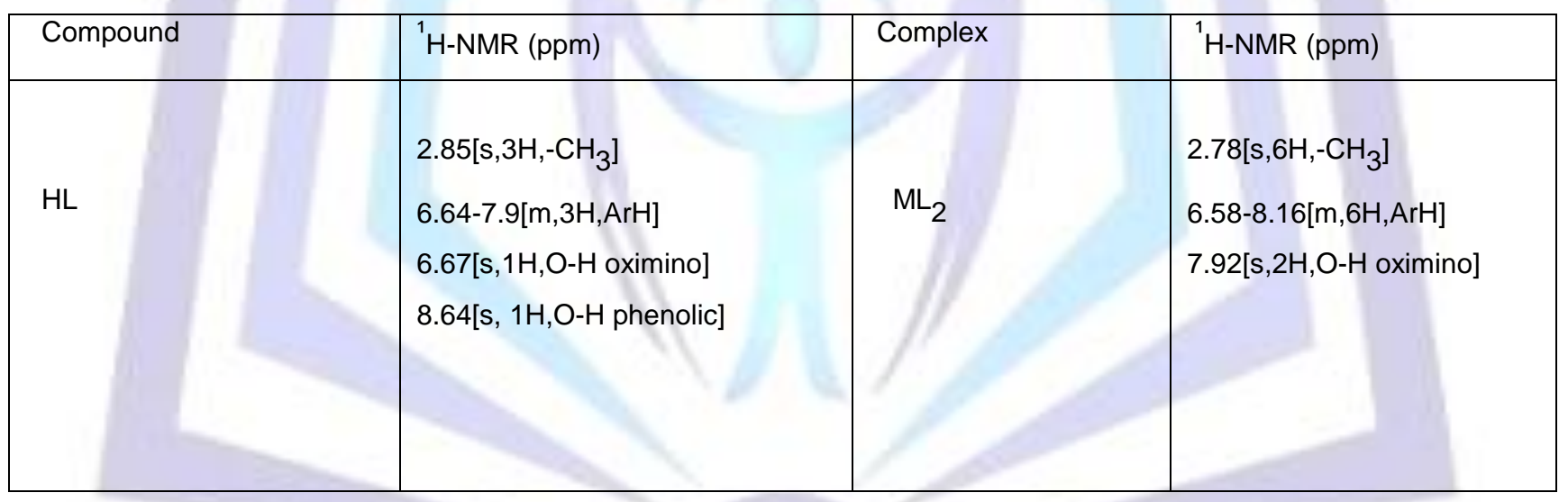

\subsection{Mass spectra}

The FAB mass spectra of $\mathrm{Co}(\mathrm{II})-\mathrm{CDHBOX}$ complex reveals its stoichiometric composition. The molecular $\left[\mathrm{M}^{+}\right]$ion peak of the complex is shown at $M / Z=415 / 419$, suggesting the stoichiometry of the complex as $\mathrm{ML}_{2}$.

\subsection{Thermogravimetric studies}

Thermo-gravimetric analysis (TGA) of $\mathrm{Co}$ (II)-CDHBOX suggests that complex is stable upto $300^{\circ} \mathrm{C}$. This indicates that the complex is not in the hydrated form. The initial decomposition shown in the TG curve was taken as a measure of the thermal stability of the complex. Sharp initial decomposition of the complex in the TG curve, is associated with a rapid loss in weight. The weight of $\mathrm{Co}$ (II)-CDHBOX complex decreases after decomposition, continuously upto $730^{\circ} \mathrm{C}$. On further heating, the weight of the residue remains constant and corresponds to CoO. The total mass loss is $85.60 \%$ (calculated value $85.66 \%$ ) which is confirmed by comparing observed and calculated mass of the pyrolysis product.

The kinetic parameters were calculated graphically by employing the Coats-Redfern equation[32]

$\log \left[-\log (1-\alpha) / T_{2}\right]=\log \left[A R / \theta E^{\circ}\left(1-2 R T / E^{\circ}\right)\right]-E^{\circ} / 2.303 R T$ 
where, $\alpha$ is the mass loss up to temperature $T, R$ is gas constant, $E^{\circ}$ is the activation energy in $\mathrm{Jmol}^{-1}, \theta$ is the linear heating rate, and the term $\left(1-2 \mathrm{RT}^{-} \mathrm{E}^{\circ}\right)=1$. A slope of the linear plot drawn between $-\log \left[-\log (1-\alpha) / \mathrm{T}^{2}\right]$ and $1 / \mathrm{T}$ gives the value of $E^{\circ}$ as $4.949 \mathrm{kjmol}^{-1}$ while its intercept (the Arrhenius constant) gives the value of $A$ (Arrhenius constant) as 74.39 . Straight line of the graph confirms the first order kinetics for thermal decomposition of the complex.

\subsection{Potentiometric study}

Proton-ligand stability constant $\left(\log \mathrm{K}_{1}\right)$ was calculated from the proton-ligand formation curve (the plot between $\bar{n} \mathrm{H}$ and $\mathrm{pH}$ ), and metal ligand stability constant ( $\log \mathrm{K}_{2}$ ) was calculated from the formation curve the plot between $\bar{n}$ and $\mathrm{pL}$ )

The thermodynamic formation constants were obtained by extrapolation of the observed formation constants to zero ionic strength on the graph between log of the stability constant and $\sqrt{ } \mu$.

The thermodynamic parameters $\Delta \mathrm{H}, \Delta \mathrm{S}$ and $\Delta \mathrm{G}$ were calculated at different temperatures (Table 3 ) and concentrations [Table 4] using the following equations:

$$
\begin{aligned}
\Delta G & =-2.303 R T \log K^{\mu=0}, \quad \Delta H=2.303 R \times\left(T_{2} \times T_{1} / T_{2}-T_{1}\right)\left(\log K_{2}{ }^{\prime \prime} / K_{1}{ }^{\prime}\right) \text { and } \\
\Delta S & =2.303 R \log K+\Delta H / T
\end{aligned}
$$

It is noted from the data that the accrued ligand (CDHBOX) behaved as a monoprotic acid due to deprotonation of the phenolic $\mathrm{OH}$ group ortho to the oximino group from which the proton was replaced by metal ion during complex formation. This was evident from the fact that metal titration curve was well separated from the ligand titration curve. The value of log $\beta_{n}$ and $\log \mathrm{K}^{\mathrm{H}}$ decreases with the increase in ionic strength. It shows that the activity of metal ion for its interaction with other molecular species decreases with the increase in the ionic strength of the medium under consideration. The protonation constant of the ligand and stability constant of metal complex decreases with the increase in temperature. The complex has a negative entropy which indicates a more ordered activated state, compensated by enthalpies of activation leading to almost the same value for the free energy of activation[29].

The ionisation depends upon the dielectric constant $(\in)$ of the medium. A solvent of low $\in$ value increases the electrostatic force between the ions, and hence facilitates the formation of molecular species resulting in the increase in $p k_{1}{ }^{H}$ value.

Table 3 Protonation constants and the Thermodynamic parameters of CDHBOX at different temperatures at $\mu=0.05 \mathrm{M}$

\begin{tabular}{|l|l|l|l|l|l|l|}
\hline $\begin{array}{l}\text { Temperature } \\
\mathrm{K}\end{array}$ & $p k_{1}^{H}$ & $\begin{array}{l}-\Delta \mathrm{G} \\
\mathrm{Kcal} / \mathrm{mol}\end{array}$ & $-\Delta \mathrm{H} \mathrm{Kcal/mol}$ & $\begin{array}{l}\Delta \mathrm{S} \\
\mathrm{cal} / \mathrm{deg} / \mathrm{mole}\end{array}$ & $\theta^{\circ} \mathrm{C}$ & $p k_{m}^{H}$ \\
\hline 293 & 12.00 & 16.11 & & 26.80 & & \\
\hline 300 & 11.86 & 16.30 & 8.26 & 26.82 & 205 & 10.10 \\
\hline 305 & 11.70 & 16.51 & & 26.81 & & \\
\hline
\end{tabular}

Table-4 Stability constant and Thermodynamic Parameters of Co(II) CDHBOX complex in Dioxane medium at different Concentrations.

\begin{tabular}{|l|l|l|l|l|l|l|l|l|l|}
\hline Conc. & \multicolumn{2}{|l|}{$\mu=0.1 \mathrm{M}$} & \multicolumn{2}{c|}{$\mu=0.05 \mathrm{M}$} & \multicolumn{3}{l|}{$\mu=0.01 \mathrm{M}$} \\
\hline & logK1 & $\log \mathrm{K} 2$ & $\log$ Bn & $\log \mathrm{K} 1$ & $\log \mathrm{K} 2$ & $\log$ Bn & log $\mathrm{k} 1$ & $\log \mathrm{K} 2$ & $\log$ Bn \\
\hline $\mathrm{HL}$ & 11.86 & & 11.86 & 11.92 & & 11.92 & 12.13 & & 12.13 \\
\hline $\begin{array}{l}\text { Co(II) } \\
\text { complex }\end{array}$ & 6.03 & 4.98 & 11.01 & 6.19 & 5.11 & 11.30 & 6.26 & 5.26 & 11.52 \\
\hline
\end{tabular}

\subsection{Antimicrobial activity}

The fungicidal and bactericidal data of the graded concentrations (0.05 to $0.40 \%)$ of $2^{\prime}$-hydroxy-4'-methoxy acetophenoneoxime(CDHBOX) and its Co(II) complex against Curvularia lunata, Fusarium oxysporum and Alternaria alternata fungi and Streproproteus, Staph, Escherchia coli, Klebsella, and pseudomonas bacteria are recorded in Tables 6 and 7 and are displayed in the form of bar diagrams [fig.4-11].The observed results reveal that antimicrobial activity of the compound is directly proportional to the concentration of the test compound. The activity for a given ligand or metal complex differs from fungus to fungus and from bacteria to bacteria. The Co(II)-CDHBOX complex has more antimicrobial activity as compared to the ligand (CDHBOX). The complex showed maximum fungicidal activity against Curvularia lunata and the least against Alternaria alternata, the overall order of fungicidal activity being $\mathrm{Cl}>\mathrm{Fu}>\mathrm{Aa}$. The complex showed 
maximum bactericidal activitiy against Staph and the least against, pseudomonas the overall order of antibacterial activity being $S t>K I S p>$ E.coli $>$ PC.

Table 5 Antifungal Activity data of $\mathrm{CDHBOX}(\mathrm{HL})$ and $\mathrm{Co}(\mathrm{II})$ complex $\mathrm{ML}_{2}$ against Alternaria alternate, Curvularia lunata, and Fusarium oxysporium .

\begin{tabular}{|l|l|l|l|l|l|l|l|l|l|l|}
\hline \multicolumn{2}{|l|}{ Alternaria alternate } & \multicolumn{3}{l|}{ Curvularia lunata } & \multicolumn{3}{l|}{ Fusarium } \\
oxysporium
\end{tabular}

Table 6 Antibacterial Activity data of CDHBOXand Co(II) complex $\mathrm{ML}_{2}$ against Klebsella, Staph, Streproproteus, Pseudomonas coccus \& E. Coli.

\begin{tabular}{|c|c|c|c|c|c|c|c|c|c|c|c|}
\hline$e^{2}$ & & $\mathrm{Kl}$ & & & & $\mathrm{S}$ & & Pse & tonas & & oli \\
\hline Concentration & $\begin{array}{l}\text { Zone of } \\
\text { Inhibition } \\
{[\mathrm{mm}]}\end{array}$ & $\mathrm{HL}$ & $\mathrm{ML}_{2}$ & $\mathrm{HL}$ & $\mathrm{ML}_{2}$ & $\mathrm{HL}$ & $\mathrm{ML}_{2}$ & $\mathrm{HL}$ & $\mathrm{ML}_{2}$ & $\mathrm{HL}$ & $\mathrm{ML}_{2}$ \\
\hline $.05 \%$ & $\begin{array}{l}\text { Inhib } \\
\text { ition } \\
\text { Zone }\end{array}$ & & & & & & & & & & \\
\hline $.10 \%$ & $\begin{array}{l}\text { Inhib } \\
\text { ition } \\
\text { Zone }\end{array}$ & & & & & & & & & & \\
\hline & $\mathrm{Al}$ & & & & & & & & & & \\
\hline $.15 \%$ & Inhib & & & & 7.2 & & & & & & \\
\hline
\end{tabular}




\begin{tabular}{|c|c|c|c|c|c|c|c|c|c|c|c|}
\hline & $\begin{array}{l}\text { ition } \\
\text { Zone }\end{array}$ & & & & & & & & & & \\
\hline & $\mathrm{Al}$ & & & & & & & & & & \\
\hline $.20 \%$ & $\begin{array}{l}\text { Inhib } \\
\text { ition } \\
\text { Zone }\end{array}$ & 9.0 & 7.0 & 8.0 & 10.2 & 6.0 & 6.9 & & & & \\
\hline & $\overline{\mathrm{Al}}$ & & 0.77 & & 1.275 & & 1.18 & & & & \\
\hline $.30 \%$ & $\begin{array}{l}\text { Inhib } \\
\text { ition } \\
\text { Zone }\end{array}$ & 10.6 & 12.0 & 10 & 11 & 8.0 & 10.0 & & & 6.0 & 6.2 \\
\hline & $\mathrm{Al}$ & & 1.13 & & 1.1 & & 1.25 & & & & 1.03 \\
\hline $.40 \%$ & $\begin{array}{l}\text { Inhib } \\
\text { ition } \\
\text { Zone }\end{array}$ & 12 & 16 & 12 & 14 & 12.0 & 14.0 & 5.6 & 6.0 & 8.2 & 8.6 \\
\hline & $\mathrm{Al}$ & & 1.33 & & 1.16 & & 1.16 & & 1.07 & & 1.04 \\
\hline
\end{tabular}

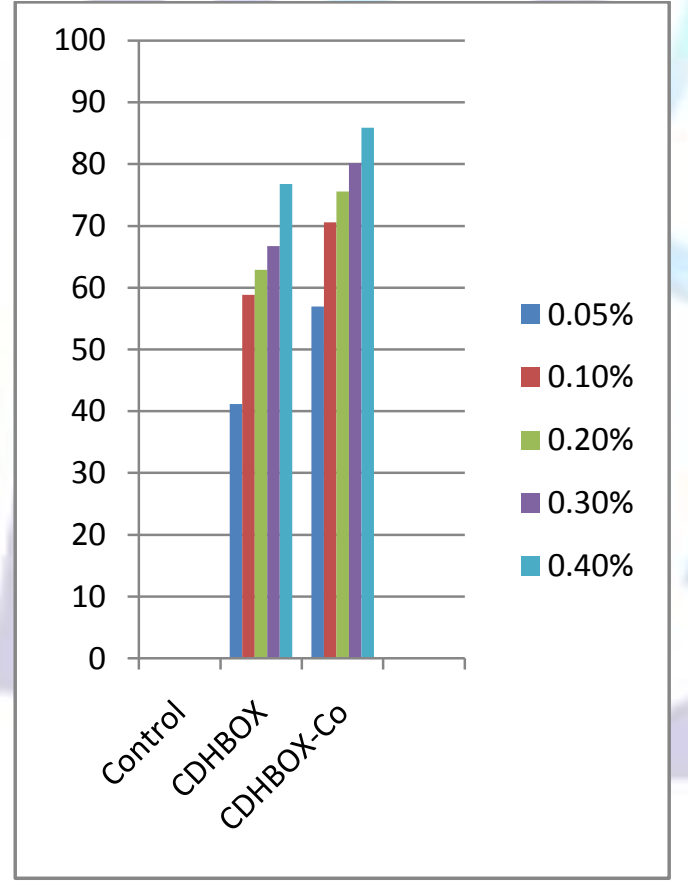

Antifungal Activity of CDHBOX and its $\mathrm{Co}$ (II) Complex against Alternaria alternate .

Fig 4

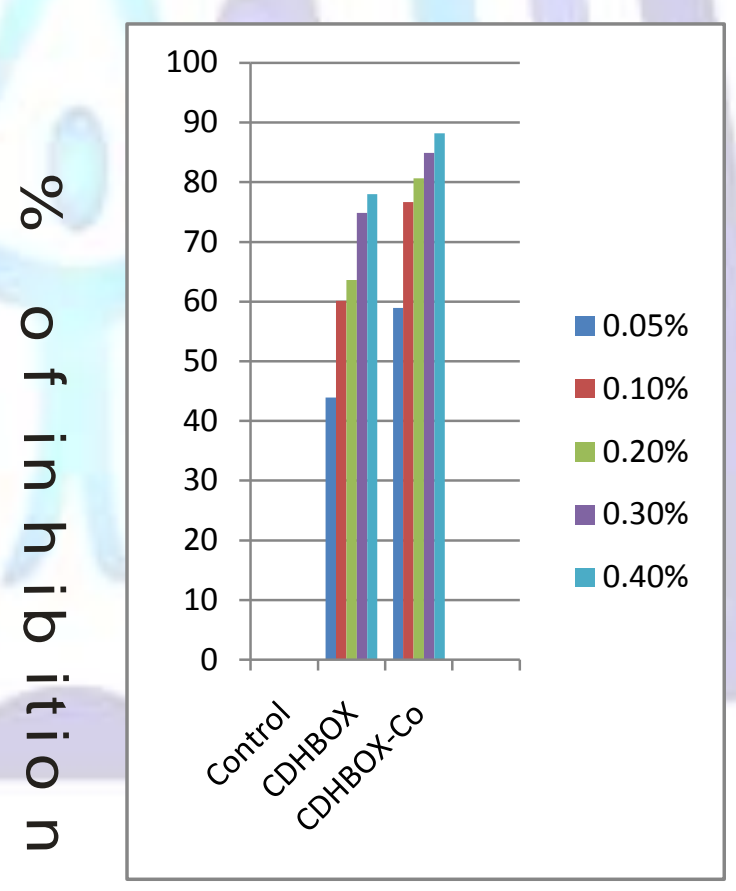

Antifungal Activity of CDHBOX and its $\mathrm{Co}$ (II) Complex against Curvularia lunata.

Fig 5 


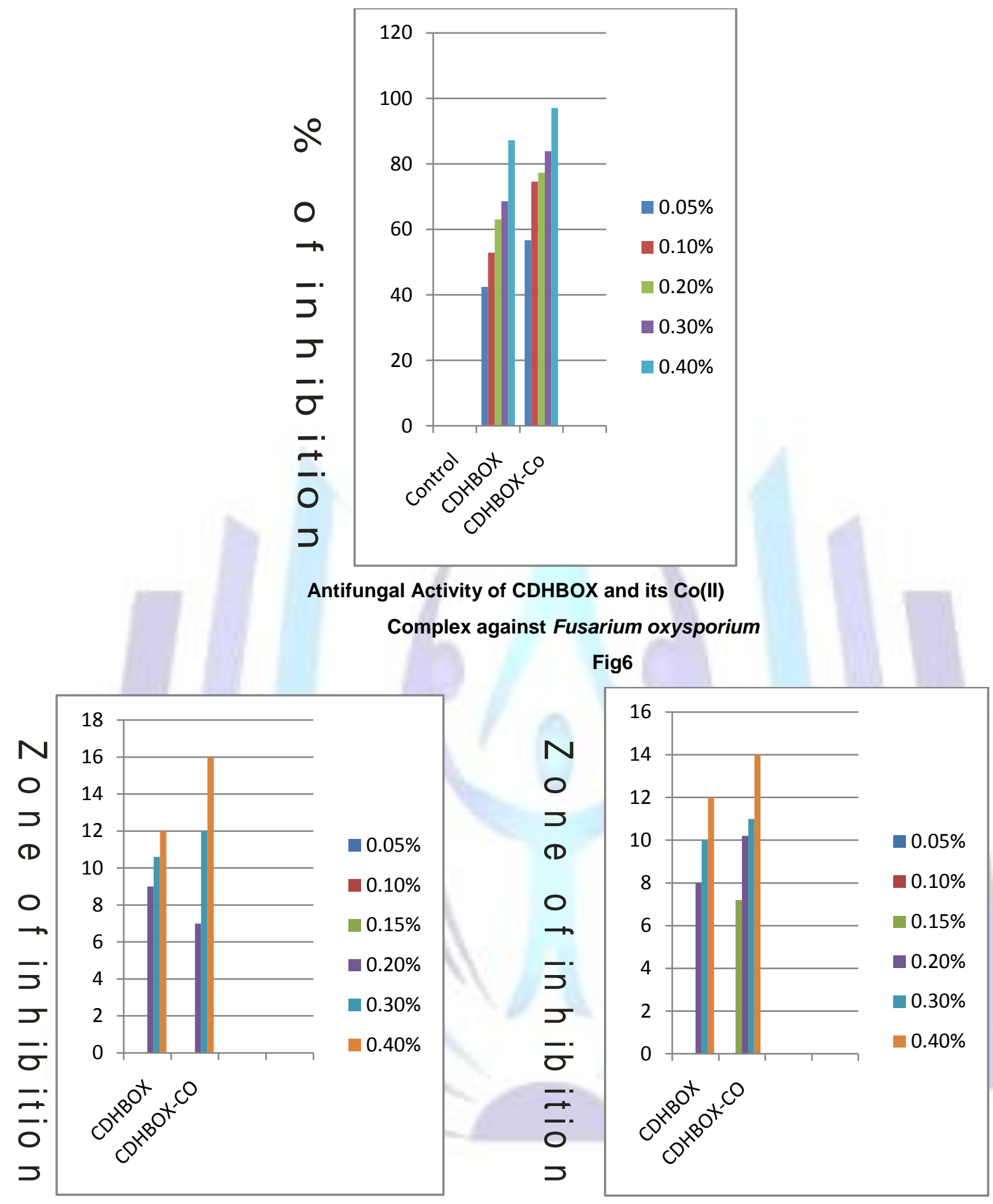

Antibacterial activity of CDHBOX and its Co(II)- Complex against Klebsella

Fig. 7
Antibacterial activity of CDHBOX and its Co(II)complex against Staph [St]

Fig. 8 


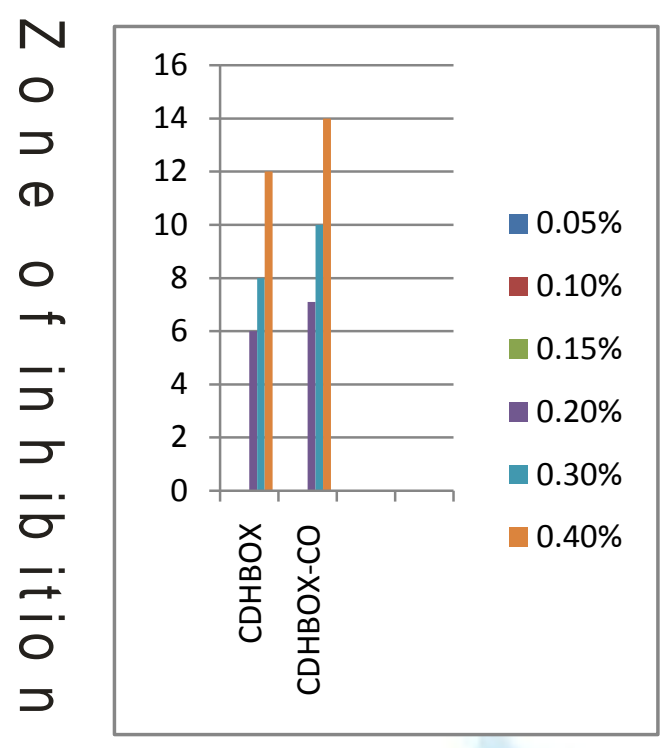

Antibacterial activity of CDHBOX and its Co(II)- Complex against Streproproteus.

Fig. 9

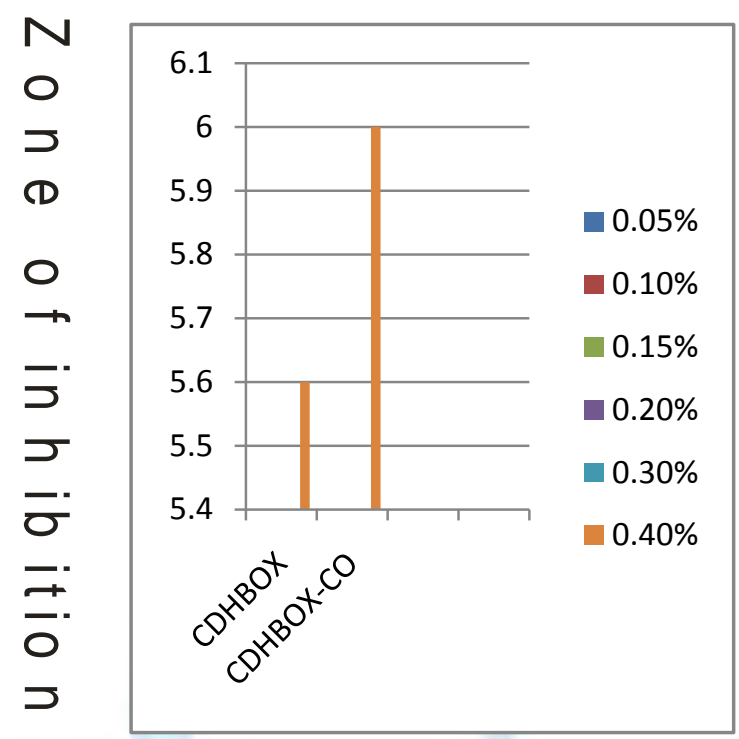

Antibacterial activity of CDHBOX and its Co(II)complex against Pseudomonas coccus.

Fig. 10
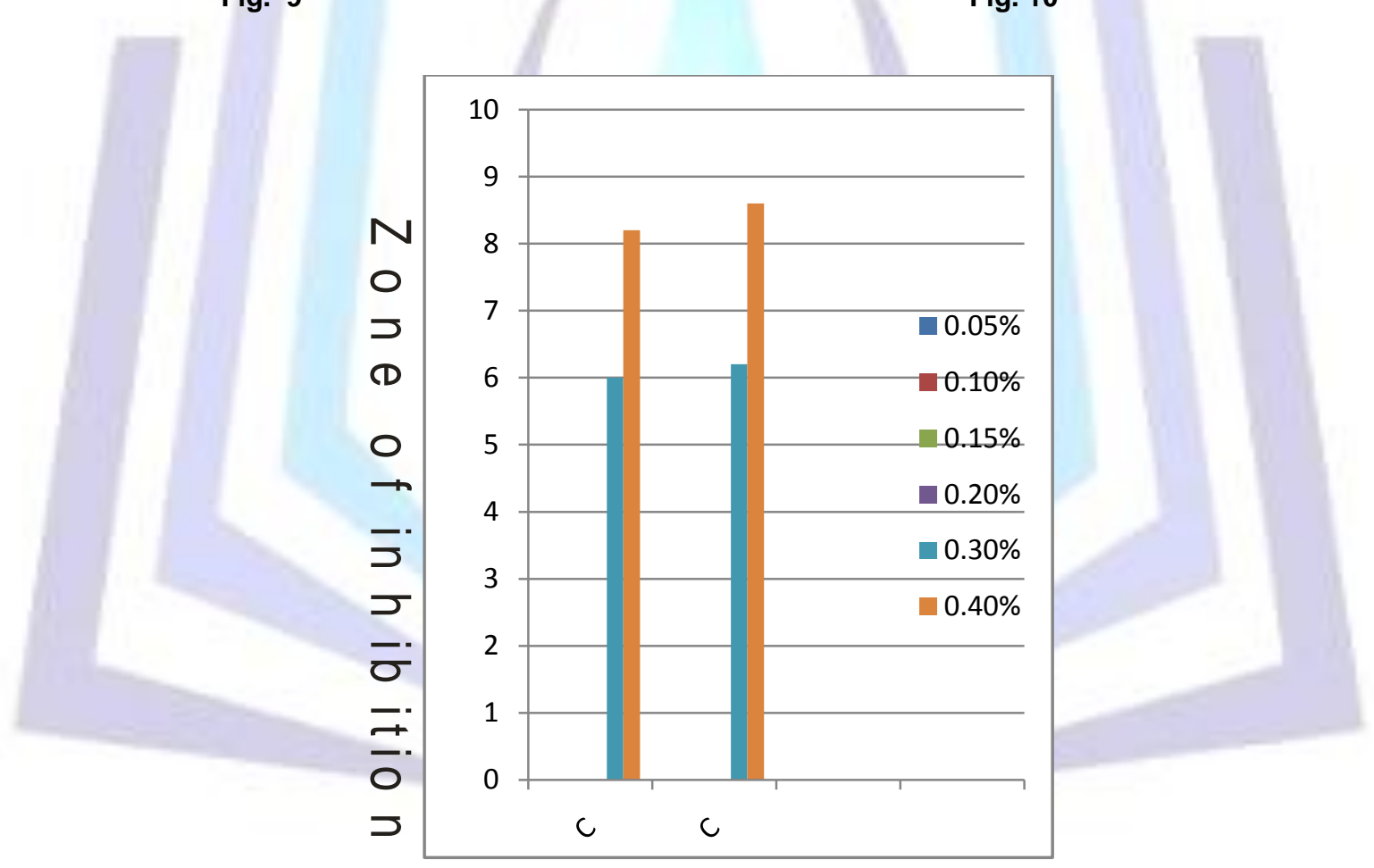

Antibacterial activity of CDHBOX and its Co(II)-

complex against E.Coli

Fig. 11

\subsubsection{Mechanism of 'Bioactivity'}

The antimicrobial studies demonstrated that chelation increases antimicrobial activity. It has been suggested that metal chelation reduces polarity of metal ion mainly because of the partial sharing of its positive charge with the donar group, and the possibility of $d$-electron delocalization occurring within the chelate ring system formed on coordination. The process of chelation thus increases the lipophilic nature of the central metal atom which, in turn, favours its permeation through the lipoid layer of the membrane [33,34 ], and the mechanism of action is understood to be alkylation of essential cellular proteins. Thus, increase in antimicrobial activity is due to faster diffusion of the free ligand with electron withdrawing group, and metal complex as a whole through the cell membrane or due to combined activity of the ligand and metal [35]. This has been supported by the experimental findings, which suggest that the compounds having higher electron density have low antimicrobial activity. 
Oxime has high antimicrobial activity as compared to semicarbazone, phenylhydrazone and phenone itself. This is attributed to the formation of dimeric and pseudomacrocyclic species by way of intermolecular hydrogen-bonding [36].<smiles></smiles>

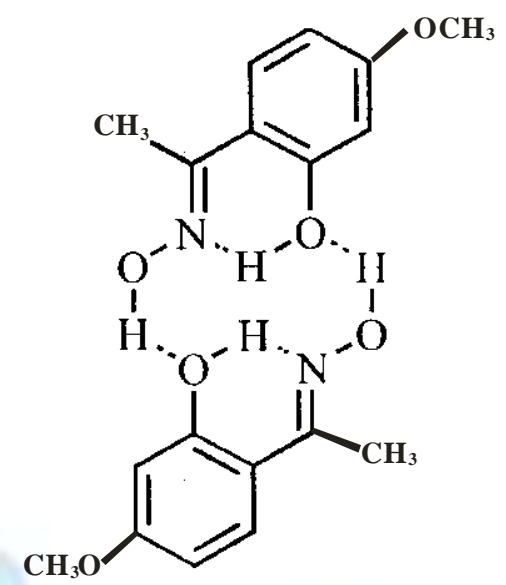

Antimicrobial properties are also found to be related to thermodynamic stability [37] and selectivity.

\section{Conclusion}

Spectrophotometric studies suggested that $\mathrm{Co}(\mathrm{II})$ ion forms only one complex with the ligand CDHBOX having the composition $\mathrm{ML}_{2}$.

The observed magnetic moment and electronic spectrum of the complex point to tetrahedral geometry and paramagnetic nature.

IR spectral studies indicate deprotonation of the phenolic group, and coordination of the

phenolic oxygen, and participation of nitrogen of the oximino group in complexation of Co (II) ion with CDHBOX. The fact is also supported by NMR spectral data. $\mathrm{FAB}$, mass spectrum of the complex reveals $\mathrm{ML}_{2}$ stoichiometric composition for the complex

TGA of the complex reveals its thermal stability in a graded manner while potentiometric study on the complex provides data to evaluate the proton-ligand stability vis a vis metal-ligand stability.

Finally, antimicrobial activity data suggest the complex to be more active than the ligand showing maximum activity against Curvularia lunata and Staph and the least against Alternaria alternata and respectively.

Structurally, the Co(II)-CDHBOX complex can be represented as

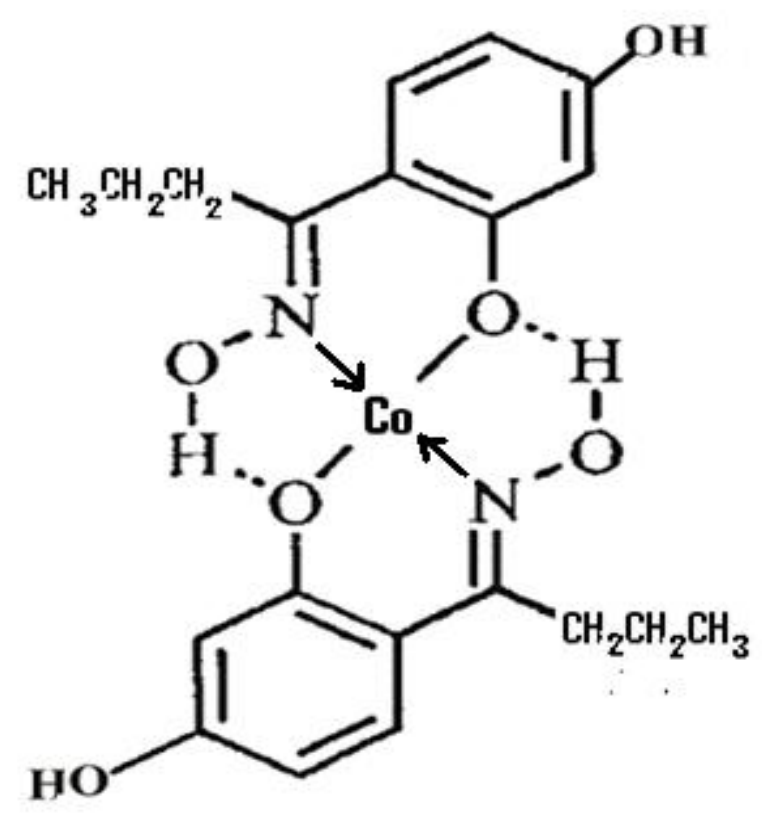

Proposed structure of Co(II)-HMAOX complex 


\section{REFERENCES}

(1) Entez Pubmed: Pubmed Indexed for Medicine, 55, 736-41,(2000)

(2) J. Kunes, J. Bazant, M.Pour, K. Waiseer, M.Slosarek, J. Jaroter :Pubmed Indexed for Medicine, 55,725-29,(2000).

(3) L.Rajabi, C. Courrages,J. Montoya, R.J. Aguilera, T.P. Primm. Lett Appl. Microbiol, 40, 212(2005)

(4) F.Rehman and Samya Mairaj . International Journal of Pharma and Biosciences,3(3), 381-390,2012

(5) F.Rehman,Samya Mairaj and Manu Bhardwaj.Oriental J of Chemistry,27 (3),1209-1214,(2011).

(6) Black Well Synergi . Applied Microbiol, 40131-212(2005).

(7) M. Miyazawa, H. Shimamura, S. Nakamura . J.Agr.Food Chem.48,4377-4380,(2000).

(8) M.Teruyaki, H.Yoshiharu, Y.Ka . Oxime derivative thereof, process for preparing thereof, Herbicidal composition and methods for the destruction of undesirable weeds. Japan Asahi chemical Ind.(1986).

(9) T. Yasuda, R. Kon, T. Nakazawa, K. Ohsawa . J. Nat. Prod. 62, 1142 (1999).

(10) R.C.Maurya,P.Patel and S.Rajput. Synth. React. Inorg. Met. Org. Chem,33,801, (2003).

(11) J.D. Joshi, S. Sharma, G. Patel and J.J. Uora . Synth.React. Inorg. Met-Org. Chem, 32, 1729 (2002)

(12) Preetam Ghogale and B.H. Mehta .Tayler and Francis Informa Academic journal, 2,247-254,(2001).

(13) N.K.B. Patel, K.K. Desai .Asian J of Chem 16(2), 1076-80,(2004).

(14) F.Rehman, Samya Mairaj . Oriental J of Chemistry. 28(1), 581-585 (2012).

(15) D.C. Prakash,A.K. Gupta, Ramanandan Prasad, A.K. Yadav . Oriental J. of Chem. 20(1), 147-150,(2004).

(16) U.K.Jetley, J. Singh, M. Shukla, F. Rehman and S.N. Rastogi . J Ind Chem. Soc. 67, 987, (1990).

(17) F.Rehman and Samya Mairaj, International J Chem Tech Research, vol 5(4),1609-1614,2013

(18) J.A. Dave and S.S Shah . Asian Journal of Chemistry 20,4141,(2008).

(19) A.I. Vogel, Text Book of Practical Organic Chemistry, $5^{\text {th }}$ Eds. Longman, Londan (1989).

(20) L.G. Van Uitert and C.G. Hass . J. Amer Chem. Soc,3192, (1953).

(21) Robinson and Shah, J Chem Soc, 1491.1934

(22) C. Saxena, D.K. Sharma, R.V. Singh : Phosphorus, Sulfer,85,9,(1993).

(23) L. Singh. M. Sharma and R.P. Singh : Biovigyanam 3,17,(1997)

(24) N. Raman,A. Kulandaisamy,C.Thangraja,K. Jeyasubra. Manian. Transit. Met. Chem., 28, 29, (2003).

(25) W.Li, Q. Wu, Y. Ye, M. Luo,L.Hu, Y.Gu, F. Niu, J. Hu, Spectrochim Acta A. 60, 2343, (2004).

(26) N.M. Shauib,A. Zaher, A. Elassar, A.EL- Dissouky, Spectrochim, Acta A, 63,714 (2006).

(27) M. Calvin and K.W. Wilson. J. Am. Chem Soc. 67,2003,(1945).

(28) H. Irving and H.S. Rossoti. J. Chem Soc. 3396,(1953).

(29) B.K. Singh. R.K. Sharma, B.S. Garg . J. Them. Anal Colorim. 84, 593(2006).

(30) W.C. Vusberg and G.R. Cooper . J. Am. Chem.64,1630,(1942).

(31) N.H. Ghosh and M.Das Gupta . Ind. J. Chem. Soc. 51, 206, (1974).

(32) A.W. Coast, J.P. Redfern : Nature 68, 201, (1964).

(33) L.S.D. Yadav, S.Singh . Indian J. Chem. 40B, 40, (2001).

(34) Z.H. Chohan, C.T. Supuran, A Scozzafava. J. of Enzyme Inhibition and Medicinal Chemistry 20,303,2005.

(35) N. Raman and S. Ravi Chandran. Asian J Chem 14,1551,(2002).

(36) G.N. ling. Physiological Chemistry and Physics and Medical, NMR. 18,(1986).

(37) F.Rehman; Ph.D. Thesis, C.C.S. University Meerut.(1991) 